\title{
Pengaruh Entrepreneurial Orientation Terhadap Strategic Entrepreneurship Serta Dampaknya Pada Kinerja Perusahaan
}

\author{
Jeanifer Henelya dan Andi Wijaya \\ Program Studi Manajemen Fakultas Ekonomi, Universitas Tarumanagara, Jakarta \\ Email: jeanifer.henelya@ymail.com
}

\begin{abstract}
The purpose of this study was to determine the effect of Entrepreneurial Orientation on Strategic Entrepreneurship and its impact on Financial Performance and Non-Financial Performance culinary business in South Jakarta. Sample Collection was done using a questionnaire in the form of paper with Probability Sampling method, Simple Random Sampling with a total 94 respondents of culinary business field. Processing data using the SmartPLS 3.0 method. The Result of this study indicate that there is a considerable influence if the Entrepreneurial Orientation with Strategic Entrepreneurship runs well it will affect Financial Performance and Non-Financial Performance.
\end{abstract}

keywords: Entrepreneurial, Strategic, business, orientation.

Abstrak: Tujuan penelitian ini adalah untuk mengetahui pengaruh Entrepreneurial Orientation terhadap Strategic Entrepreneurship serta dampaknya pada Financial Performance dan Non-Financial Performance pada UMKM kuliner di Jakarta Selatan. Pengumpulan sample dilakukan dengan menggunakan kuesioner dalam bentuk Kertas dengan metode probability Sampling berjenis Simple Random Sampling dengan total 94 responden UMKM di bidang Kuliner. Pengolahan data menggunakan metode SmartPLS 3.0. Hasil penelitian ini menunjukan bahwa terdapat pengaruh yang cukup besar apabila Entrepreneurial Orientation dengan Strategic Entrepreneurship berjalan dengan baik maka akan mempengaruhi Financial Performance dan Non-Financil Performance.

Kata Kunci: Kewirausahaan, Strategi, Bisnis, Orientasi.

\section{LATAR BELAKANG}

Pertumbuhan industri makanan dan minuman mulai menjadi andalan sebagai penopang pertumbuhan ekonomi nasional dan manufaktur. Pada 2019 sektor makanan dan minuman diyakini terus menjadi primadona, terutama pada sektor industri pariwisata yang mengembangkan wisata kuliner.

Melihat dari berita tersebut, maka dapat disimpulkan bahwa memang UMKM yang bergerak di bidang kuliner memiliki persaingan yang sangat ketat. Persaingan yang ketat harus dapat dihadapi, salah satunya dengan kinerja bisnis yang baik. Business Performance 
(Performa Bisnis) merupakan istilah umum yang digunakan untuk menilai kinerja suatu organisasi bisnis dalam memaksimalkan segala sumber daya yang dimilikinya

\section{KAJIAN TEORI}

UMKM (Usaha Mikro kecil menengah) adalah unit usaha produktif yang berdiri sendiri, yang dilakukan oleh orang perorangan atau Badan Usaha disemua sektor ekonomi (Tambunan, 2012:2). Di Indonesia, definisi UMKM diatur berdasarkan Undang-Undang Republik Indonesia Nomor 20 Tahun 2008 tentang Usaha Mikro, Kecil, dan Menengah.

Menurut Louis E. Boone (2007:5), bisnis (business) terdiri dari seluruh aktivitas dan usaha untuk mencari keuntungan dengan menyediakan barang dan jasa yang dibutuhkan bagi system perekonomian, beberapa bisnis memproduksi barang berwujud sedangkan yang lain memberikan jasa. Menurut Zimmerer (2005:3), seorang wirausaha adalah seseorang yang menciptakan sebuah bisnis baru dengan mengambil resiko dan ketidakpastian demi mencapai keuntungan dan pertumbuhan dengan cara mengidentifikasi peluang dan menggabungkan sumber daya yang diperlukan untuk mendirikannya. Menurut Salehi et al (2013). didefinisikan Orientasi kewirausahaan sebagai proses pembuatan strategi untuk tindakan dan keputusan kewirausahaan. Ini juga dapat didefinisikan sebagai perilaku dan karakteristik seperti pengambilan keputusan dan praktik, yang mengarahkan perusahaan ke entri baru.

Menurut Altuntaş, Gültekin., İ. Ü, Yüksekokulu., dan Ulaştırma ve Lojistik. (2014). Kewirausahaan strategis didefinisikan sebagai kombinasi simultan dari tindakan kewirausahaan yang terkait dengan perilaku pencarian peluang dan tindakan strategis yang terkait dengan perilaku pencarian keuntungan kompetitif untuk menciptakan nilai. Menurut Batchimeg, Bayaraa. (2017). Financial performance adalah tingkat sejauh mana sebuah perusahaan mampu mencapai target dari sisi keuangan yang diharapkan atau dijadikan acuan di awal periode. Financial performance dapat diukur menggunakan beberapa rasio seperti ROA, ROE, NPM dan sebagainya. Menurut Hornungova (2016) Non-Financial performance adalah tolak ukur keberhasilan perusahaan yang diukur menggunakan skala yang bersifat kualitatif meliputi hal-hal mencakup pemasaran, sumber daya manusia, teknologi dan sebagainya. Non-financial performance dapat diukur menggunakan beberapa rasio seperti kepuasan konsumen, kepuasan pelanggan.

Kerangka pemikiran dalam penelitian ini adalah sebagai berikut:

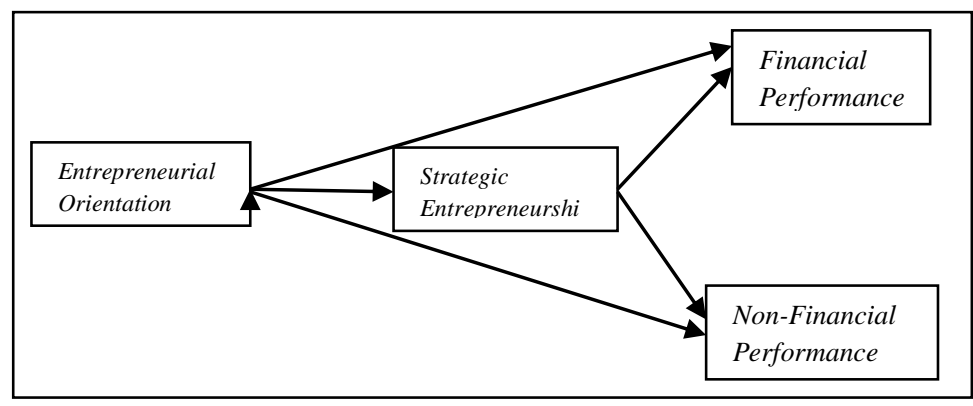


Berdasarkan kerangka pemikiran di atas, hipotesis yang digunakan dalam penelitian ini adalah sebagai berikut:

H1 : Entrepreneurial Orientation berpengaruh positif signifikan terhadap Strategic Entrepreneurship pada UMKM kuliner di Jakarta Selatan.

$\mathrm{H} 2$ : Strategic Entrepreneurship berpengaruh positif signifikan terhadap Financial Performance pada UMKM kuliner di Jakarta Selatan.

H3 : Strategic Entrepreneurship berpengaruh positif signifikan terhadap Non-Financial Performance pada UMKM kuliner di Jakarta Selatan.

H4 : Strategic Entrepreneurship memediasi pengaruh Entrepreneurial Orientation terhadap Financial Performance pada UMKM kuliner di Jakarta Selatan.

H5 : Strategic Entrepreneurship memediasi pengaruh Entrepreneurial Orientation terhadap Non-Financial Performance pada UMKM kuliner di Jakarta Selatan.

H6 : Entrepreneurial Orientation berpengaruh positif signifikan terhadap Financial Performance pada UMKM kuliner di Jakarta Selatan.

H7 : Entrepreneurial Orientation berpengaruh positif signifikan terhadap NonFinancial Performance pada UMKM kuliner di Jakarta Selatan.

\section{METODOLOGI}

Dalam penelitian ini yang menjadi populasi adalah seluruh UMKM di bidang kuliner di Jakarta Selatan berjumlah 1570 UMKM. sampel dalam penelitian ini adalah sebagian dari seluruh UMKM di bidang kuliner di Jakarta Selatan. Dalam penelitian ini, metode perhitungan sampel yang digunakan adalah metode Slovin dimana rumus perhitungan slovin adalah $\mathrm{N}=$ populasi , e = tingkat kesalahan , $\mathrm{n}=$ sampel. Sehingga rumus tersebut dapat dijelaskan sebagai berikut:

$\mathrm{n}=\frac{N}{1+N(e)^{2}}=\frac{1570}{1+1570(0.1)^{2}}=\frac{1570}{1+1570 x 0.001}=\frac{1570}{16.7}=94$ UMKM di bidang Kuliner

Untuk memastikan akurasi pengambilan sampel, digunakan metode probability sampling dengan pendekatan simple random sampling. Kriteria dalam penelitian ini adalah Perusahaan di bidang kuliner masuk dalam kriteria UMKM dan bukanlah anak cabang atau franchise

Subjek dalam penelitian ini berdasarkan perusahaan UMKM yang telah terbagi menjadi 3 golongan, yaitu golongan mikro, golongan kecil dan golongan menengah. Dengan Menggunakan model pengukuran validitas yang digunakan dalam penelitian ini terdiri dari Convergent validity, Discriminant Validity, Average Variance Extracted (AVE). Dalam uji reliabilitas, penelitian ini terdiri dari cronbach's alpha dan composite reliability. Peneliti menggunakan cronbach's alpha serta composite reliability dalam hasil uji reliabilitas. Di sisi lain terdapat pengujian model struktural yang dilakukan yang terdiri dari uji koefisien determinasi $\left(\mathrm{R}^{2}\right)$, nilai path coefficients, uji pengukuran $\mathrm{Q}-$ Square $\left(\mathrm{Q}^{2}\right)$, Effect Size, Pengujian Nilai Koefisien Jalur dan menggunakan Uji T. Dan menggunakan analisis data SmartPLS 3.0. 


\section{Hasil Uji Statistik}

Dalam hasil uji statistik penelitian ini, di bawah ini disajikan hasil uji validitas yang terdiri dari Convergent Validity, Discriminant Validity, Average Variance Extracted $(A V E)$.

Tabel 1. Tabel Convergent Validity

\begin{tabular}{|c|c|c|c|c|}
\hline & $\begin{array}{c}\text { Entrepreneurial } \\
\text { Orientation }\end{array}$ & $\begin{array}{c}\text { Financial } \\
\text { Performance }\end{array}$ & $\begin{array}{l}\text { Non-Financial } \\
\text { Performance }\end{array}$ & $\begin{array}{c}\text { Strategic } \\
\text { Entrepreneurship }\end{array}$ \\
\hline EO1 & 0,850 & & & \\
\hline EO2 & 0,851 & & & \\
\hline EO3 & 0,848 & & & \\
\hline EO4 & 0,854 & & & \\
\hline EO5 & 0,861 & & & \\
\hline EO6 & 0,830 & & & \\
\hline FP1 & & 0,875 & & \\
\hline FP2 & & 0,885 & & \\
\hline FP3 & & 0,868 & & \\
\hline NFP1 & & & 0,858 & \\
\hline NFP2 & & & 0,870 & \\
\hline NFP3 & & & 0,885 & \\
\hline NFP4 & & & 0,894 & \\
\hline SE1 & & & & 0,830 \\
\hline SE2 & & & & 0,849 \\
\hline SE3 & & & & 0,845 \\
\hline SE4 & & & & 0,868 \\
\hline SE5 & & & & 0,837 \\
\hline SE6 & & & & 0,851 \\
\hline SE7 & & & & 0,867 \\
\hline SE8 & & & & 0,777 \\
\hline SE9 & & & & 0,863 \\
\hline
\end{tabular}

Sumber: hasil pengolahan data SmartPLS 3.0

Berdasarkan tabel diatas dapat dilihat bahwa nilai Outer Loadings dari setiap indikator telah melebihi 0.7 yang merupakan syarat dari Outer Loading tersebut sehingga dapat dikatakan bawha data tersebut lolos. Berikut adalah tabel Disciminant Validity dari setiap variabel yaitu sebagai berikut: Berikut adalah tabel Average Variance Extracted (AVE) dari setiap variabel yaitu sebagai berikut: 
Tabel 2. Tabel Average Variances Extracted

\begin{tabular}{|l|c|}
\hline & Average Variance Extracted (AVE) \\
\hline Entrepreneurial Orientation & 0.721 \\
\hline Financial Performance & 0.768 \\
\hline Non-Financial Performance & 0.769 \\
\hline Strategic Entrepreneurship & 0.711 \\
\hline
\end{tabular}

Sumber: hasil pengolahan data SmartPLS 3.0

Dari tabel 3, dapat dilihat bahwa Entrepreneurial Orientation, Financial performance, Non-Financial Performance dan Strategic Entrepreneurship telah melebihi 0.5 yang merupakan syarat dari Average Variance Extracted. Berikut adalah tabel Composite Reliability dari setiap variabel yaitu sebagai berikut:

Tabel 3. Hasil Pengujian Reliabilitas

\begin{tabular}{|l|c|c|}
\hline & Composite Reliability & Cronbach's Alpha \\
\hline Entrepreneurial Orientation & 0.939 & 0.923 \\
\hline Financial Performance & 0.908 & 0.849 \\
\hline Non-Financial Performance & 0.930 & 0.900 \\
\hline Strategic Entrepreneurship & 0.957 & 0.949 \\
\hline
\end{tabular}

Sumber: hasil pengolahan data SmartPLS 3.0

Dari tabel 4, dapat dilihat bahwa Entrepreneurial Orientation, Financial Performance, Non-Financial Performance dan Strategic Entrepreneurship telah melebihi 0.6 yang merupakan syarat dari Composite Reliability, dan dapat disimpulkan bahwa Entrepreneurial Orientation, Financial Performance, Non-financial Performance, Strategic Entrepreneurship telah melebihi 0.6 yang merupakan syarat dari tabel Cronbach's Alpha. Berikut Pengujian hasil Path Coefficient sebagai berikut:

Tabel 4. Hasil Path Coefficient

\begin{tabular}{|l|c|c|}
\hline & $\begin{array}{c}\text { Original } \\
\text { Sample }\end{array}$ & $\begin{array}{c}\text { P } \\
\text { Values }\end{array}$ \\
\hline Entrepreneurial Orientation__> Financial Performance & 0.525 & 0.020 \\
\hline $\begin{array}{l}\text { Entrepreneurial Orientation_ >> Non-Financial } \\
\text { Performance }\end{array}$ & 0.401 & 0.058 \\
\hline $\begin{array}{l}\text { Entrepreneurial Orientation_ -> Strategic } \\
\text { Entrepreneurship_ }\end{array}$ & 0.966 & 0.000 \\
\hline Strategic Entrepreneurship_-> Financial Performance & 0.298 & 0.173 \\
\hline $\begin{array}{l}\text { Strategic Entrepreneurship_-> Non-Financial } \\
\text { Performance }\end{array}$ & 0.475 & 0.027 \\
\hline
\end{tabular}


Sumber: hasil pengolahan data SmartPLS 3.0

Tabel 5. Tabel Indirect Effect

\begin{tabular}{|l|c|c|}
\hline & Original Sample & P Values \\
\hline $\begin{array}{l}\text { Entrepreneurial Orientation_-> Strategic } \\
\text { Entrepreneurship_-> Financial Performance }\end{array}$ & 0.288 & 0.176 \\
\hline $\begin{array}{l}\text { Entrepreneurial Orientation_-> Strategic } \\
\text { Entrepreneurship_-> Non-Financial } \\
\text { Performance }\end{array}$ & & \\
\hline
\end{tabular}

Sumber: hasil pengolahan data SmartPLS 3.0

Berdasarkan Hasil Path Coefficient dan Indirect Effect yang terdapat pada gambar 1, tabel 4,5 diatas, $\mathrm{H} 2, \mathrm{H} 4, \mathrm{H} 7$ ditolak karena tidak mencapai batas minimum $P$ values $<0.05$.

Dan berikut adalah gambaran regresi yang terbentuk dalam penelitian ini:

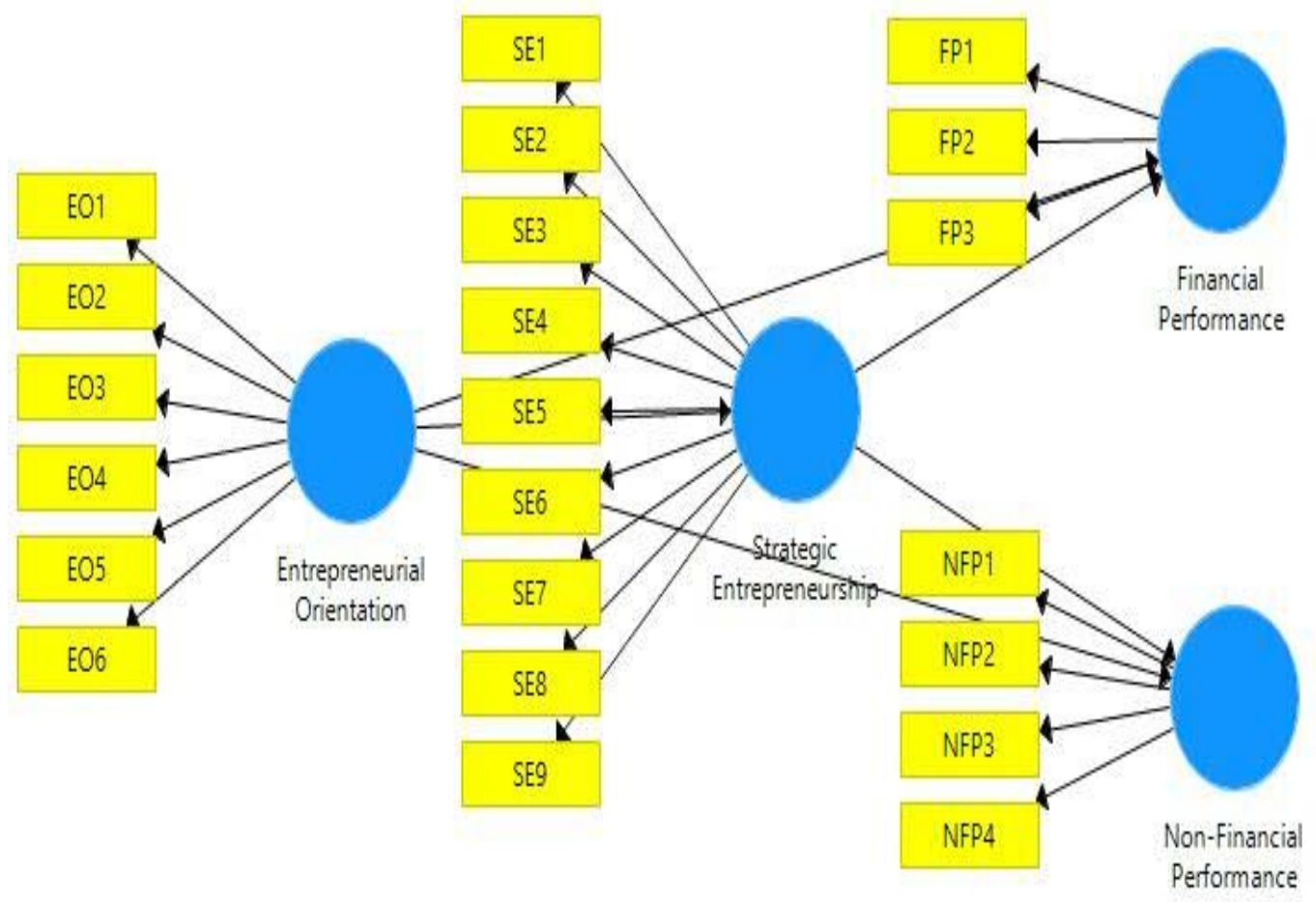

Sumber: SmartPLS 3.0

\section{DISKUSI}

Pembahasan dalam penelitian kali ini akan membahas mengenai hasil penelitian yang telah dilakukan. Penelitian dilakukan dengan melakukan pengumpulan sebanyak 94 responden dari Pemilik/manajer/staff UMKM di daerah Jakarta Selatan.Sampel yang diambil memiliki kategori yang dibagi menjadi Lama berdirinya perusahaan, jumlah karyawan dan Jumlah omzet perusahaan per tahun. Karakteristik Entrepreneurial 
Orientation dibidang kuliner yaitu arahan dari atasan restoran untuk menghindari hal-hal yang beresiko, adanya menu-menu yang berbeda dari pesaing, serta kecenderungan untuk tidak bersaing dengan perusahaan atau restoran yang sejenis. Pada Strategic Orientation itu sendiri terbentuk dari Entrepreneurial Orientation yang baik. Hal ini karena adanya orientasi Entrepreneurial, maka perusahaaan cenderung lebih terfokus pada perusahaan sendiri dan berusaha untuk menciptakan sesuatu yang berbeda. Pada bidang kuliner untuk mengeluarkan biaya untuk membuat menu makanan baru, serta adanya perbaikan dan pembenahan untuk mendorong adanya perubahan merupakan Financial Performance yang dipengaruhi oleh Strategic Entrepreneurship akan tetapi hal ini dapat terjadi apabila Strategic Entrepreneurship berjalan dengan baik sehingga akan memunculkan perubahan dan pengembangan dari beberapa segi bisnis. Strategix Entrepreneurship memberikan peranan penting pada Non-Financial Performance di bidang kuliner seperti pengembangan menu-menu baru, mengadopsi strategi untuk dapat terus bersaing sehingga Strategic Entrepreneurship memiliki peranan penting pada Non-Financial Performance karena apabila Strategic Entrepreneurship berjalan dengan baik secara tidak langsung akan meingkatkan kinerja dari sebuah perusahaan baik dari segi Non-Financial Performance. Pada perusahaan yang telah menjalankan Entrepreneurial Orientation dengan baik akan berpengaruh terhadap kinerja perusahaan sehingga dapat meningkatkan finansial dari perusahaan. peningkatan yang terjadi pada Non-Financial Performance tidak berdasarkan Entrepreneurial Orientation walaupun Entrepreneurial Orientation telah berjalan dengan baik.

\section{PENUTUP}

Tujuan untuk melakukan penelitian ini dalah untuk mengetahui apakah Strategic Entrepreneurship yang memediasi Entrepreneurial Orientation mempengaruhi Financial Performance dan Non-Financial Performance. Penelitian ini melibatkan 94 responden pelaku UMKM kuliner di Jakarta Selatan. Pengolahan data menggunakan Smart PLS 3.0. Berikut adalah kesimpulan yang didapatkan dari hasil penelitian dan analisis yang ada di bab IV: (1) Terdapat pengaruh pada Entrepreneurial Orientation terhadap Strategic Entrepreneurship pada UMKM kuliner di Jakarta Selatan. (2) Tidak terdapat pengaruh pada Strategic Entrepreneurship terhadap Financial Performance pada UMKM kuliner di Jakarta Selatan. (3) Terdapat pengaruh pada Strategic Entrepreneurship terhadap NonFinancial Performance pada UMKM kuliner di Jakarta Selatan. (4) Terdapat pengaruh pada Entrepreneurial Orientation terhadap Financial Performance pada UMKM kuliner di Jakarta Selatan. (5) Tidak terdapat pengaruh pada Entrepreneurial Orientation terhadap Non-Financial Performance pada UMKM kuliner di Jakarta Selatan. (6) Tidak terdapat pengaruh Strategic Entrepreneurship yang memediasi Entrepreneurial Orientation terhadap Financial Performance pada UMKM kuliner di Jakarta Selatan. (7) Terdapat pengaruh pada Strategic Entrepreneurship yang memediasi Entrepreneurial Orientation terhadap Non-Financial Performance pada UMKM kuliner di Jakarta Selatan. 
Berikut adalah beberapa saran yang disarankan oleh peneliti, yaitu: (1) Dilihat bahwa pada Entrepreneurial Orientation perusahaan menekankan pada resiko yang rendah sehingga proses pengambilan keputusan yang matang dapat meningkatkan kinerja perusahaan, memajukan perusahaan supaya selalu berusaha untuk menjalankan perusahaan dengan penuh pertimbangan dan selalu menghindari hal-hal beresiko yang dapat menghambat keberlangsungan perusahaan. (2) Dilihat bahwa pada Strategic Entrepreneurship perusahaan selalu mendorong munculnya strategi-strategi yang unik, inovasi yang baru yang berbeda dengan pihak lain sehingga dapat meningkatkan nilai pada perusahaan tersebut yang secara tidak langsung akan menarik minat konsumen sehingga dapat menjadi perusahaan yang berbeda dengan pesaing lainnya dan dapat terus bersaing dengan UMKM di bidang kuliner lainnya. (3) DIsaran untuk peneliti selanjutnya supaya dapat memperluas jangkauan pengambilan sample dan wilayah yang dicakupi sehingga dapat memperkuat dan melengkapi penelitian yang telah dilakukan sebelumnya dengan karakteristik responden lainnya. (4) disarankan untuk meneliti variabel-variabel lainnya yang tidak digunakan dalam penelitian ini supaya dapat mengetahui hal-hal lainnya yang dapat memperngaruhi keberhasilan bisnis UMKM di bidang kuliner ini.

\section{DAFTAR PUSTAKA}

Deniz Kantur (2016) "Strategic entrepreneurship: mediating the entrepreneurial orientation-performance link", Management Decision, Vol. 54 No. 1, pp. 24-43

Martinez, Eduardo Vega., Serna, Maria del Carmen Martinez., Guzman, Gonzalo Maldonado. (2018). The Relationship Between Market Orientation, Entrepreneurial Orientation and Learning Orientation on Innovation and its Effect on Performance in Mexican SMEs. International Business Management, 12: 132-144.

Tambunan, Tulus, (2012). Mikro Kecil dan Menengah di Indonesia : isu-isu penting”, Jakarta : LP3ES, 2012.

UNDANG-UNDANG REPUBLIK INDONESIA NOMOR 20 TAHUN 2008 TENTANG USAHA KECIL, MIKRO DAN MENEGAH.

Amirullah, Hardjanto. 2005. Pengantar Bisnis, Edisi 1. Graha Ilmu, Yogyakarta.

Buchari Alma, 1993, Pengantar Bisnis, Bandung, AlfaBeta

Louise, E. Boone. (2007). Contemporary Marketing Thirteenth (13th) Edition. San Fransisco: South-Western College Pub.

Kasmir. 2006. Kewirausahaan. Jakarta: PT Raja Grafindo Persada

As'ad, Mohammad. (2009). Seri Ilmu Sumber Daya Manusia: Psikologi Industri, Edisi IV. Yogyakarta: Liberty.

Suryana. 2009. Kewirausahaan, Pedoman Praktis, Kiat dan Proses Menuju Sukses, PT.Salemba Empat. Jakarta.

Thomas W. Zimmerer \& Norman M. Scarborough. 2005. Kewirausahaan dan Manajemen Bisnis Kecil, Jakarta: Indeks.

Thibault, Melissa. (2016). The Effect of Entrepreneurial Orientation on Teacher satisfaction and Retention. A dissertation submitted to the Graduate Faculty of North Carolina State University. Raleigh, North Carolina 
Dharmanegara, Ida Bagus Agung dan I Made Yogiarta, I Made Setena. (2018). Entrepreneurial Orientation, Business Strategy, and Small Medium Enterprise's Performance. International Journal of Academic Research in Business and Social Sciences, 8(11), 484-494.

Salehi, N. Assoc. Rozeyta, Omar \& Ismail, B. Ismail. (2013). Exploring the Entrepreneurial Antecedents of Absorptive Capacity and Its Impact on Open, Radical and Incremental Innovation. Journal of Basic and Applied Scientific Research. ISSN 2090-4304. 3(4) 327-340.

Korosteleva, J. and Belitski, M. (2017) Entrepreneurial dynamics and higher education institutions in the postcommunist world. Regional Studies, 51 (3). pp. 439ᄀ453. ISSN 00343404.

Zafar, Fareeha \& Sheikh, Sara (2013). Integrating Strategies Of EntrepreneurshipGourmet Pakistan: Case Study From Pakistan. European Journal of Business, Economics and Accountancy Vol. 1, No. 1, 2013.

Altuntaş, Gültekin., İ. Ü, Yüksekokulu., dan Ulaştırma ve Lojistik. (2014). The Relationship Between Entrepreneurship And Strategic Management: A Strategic Entrepreneurship Model And Test On Borsa Istanbul Bist-100 Index.

Pourali,M Reza., Taghavi, Mehdi., Mortazavi, J. Seyed. Samadi, Mahmoud. (2014). The Study of Relationship between the Criteria of Value Creation and Companies Success Degree with Fuzzy Approach: Evidence From IRAN. Applied mathematics in Engineering, Management and Technology 2 (5) 2014:214-219.

Nguyen, Oanh Kieu., Ethan A. Halm., dan Anil N. Makam. (2016). Relationship Between Hospital Financial Performance and Publicly Reported Outcomes. J Hosp Med. $2016 \mathrm{Jul} ; 11(7)$ : 481-488.

Batchimeg, Bayaraa. (2017). Financial Performance Determinants of Organizations: The Case of Mongolian Companies. Journal of Competitiveness. Vol. 9, Issue 3, pp. 22 33, September 2017. ISSN 1804-171X.

Ahmad, K., Zabri, S.M. (2016), The application of non-financial performance measurement in malaysian manufacturing firms. Procedia Economics and Finance 35, 476-484.

Ahmad, Kamilah dan Zabri, S. Mohamed. (2016). The effect of Non-financial Performance Measurement System on Firm Performance. International Journal of Economics and Financial Issues, 2016, 6(S6) 50-54.

Hornungova, Jana. (2017). Non financial Performance Evaluation As Significant Area Of Strategic Business Management. Business: Theory and Practice, 2017, 18: 71-78.

Tarigan, Josua dan Widjaja, C. Deborah. (2014). The Relationship between Non-Financial Performance and Financial Performance Using Balanced Scorecard Framework: A Research in Education Context. Journal of Economics, Business and Management, Vol. 2, No. 1, February 2014.

Rigtering, J.P. Coen., Eggers, Fabian., Chang, Man-Ling. (2017). Entrepreneurial orientation, strategic planning and firm performance: The impact of national cultures. European Journal of International Management 11(3):301.

Gupta S, et al. (2005) Temporal Expression Profiling Identifies pathways mediating effect of casual variant on phenotype. PLoS Genet11(6).

Żur, A., (2013). Entrepreneurial Orientation and Firm Performance - Challenges for Research and Practice. Entrepreneurial Business and Economics Review, 1(2), pp. 7-28. 
Jyoti, Jeevan. (2015). Impact of Strategic Entrepreneurship on Financial Performance: A Study of Hosiery Industry in India. pp.184-196.

Kuratko, D.F. \& Morris, M.H., (2018), 'Corporate entrepreneurship: A critical challenge for educators and researchers', Entrepreneurship Education and Pedagogy 1(1), 4260. https://doi.org/10.1177/2515127417737291

Charupongsopon, Wittaya \& Puriwat, Wilert. (2017). "The Influence of Entrepreneurial Orientation and Family Business's Resources and Capabilities on İarketing Performances," European Research Studies Journal, European Research Studies Journal, vol. O(2A), pages 150-163.

Kurtulmuşa, B. E., Warner, B. (2015). Entrepreneurial orientation and perceived financial performance. Does environment always moderate EO performance relation. Proceida-Social and Behavioural Sciences, 20(October 2015), 739-748. https://doi.org/10.1016/j.sbspro.2015.10.151

Davis, L. Justin., Bell, Greg., Payne, G. Tyge., Kreiser, M. Patrick. (201). Entrepreneurial Orientation and Firm Performance: The Moderating Role of Managerial Power. American Journal of Business 25(2):41-54.

Zur, A., (2013). Entrepreneurial Orientation and Firm Performance - Challenges for Research and Practice. Entrepreneurial Business and Economics Review, 1(2), pp. 728.

Sedyowidodo, Urip., Basbeth, Entrepreneurial Orientation and Business Performance: The Mediating Role of Organizational Learning and Innovation in State Owned Enterprise (SOE) in Indonesia.

Al-Swidi, A.K., \&Mahmood,R.(2012). TQM and organizational performance: The role of organizational culture. African Journal of Business Management, 6(13): 4717-4727. DOI: 10.5897/AJBM11.2016.

Sugiyono. (2014). Metode Penelitian Pendidikan Pendekatan Kuantitatif, Kualitatif, dan $R \& D$. Bandung: Alfabeta.

Arikunto, Suharsimi. 2013. Prosedur Penelitian Suatu Pendekatan Praktik. Rineka. Cipta: Jakarta.

Sugiyono. 2013. Metode Penelitian Pendidikan Pendekatan Kuantitatif, Kualitatif, dan $R \& D$. Bandung: Alfabeta.

Sugiyono. (2017). Metode Penelitian Kuantitatif, Kualitatif, dan R\&D. Bandung : Alfabeta, CV.

Sugiyono. (2016). Metode Penelitian Kuantitatif, Kualitatif dan R\&D. Bandung: PT Alfabet. 